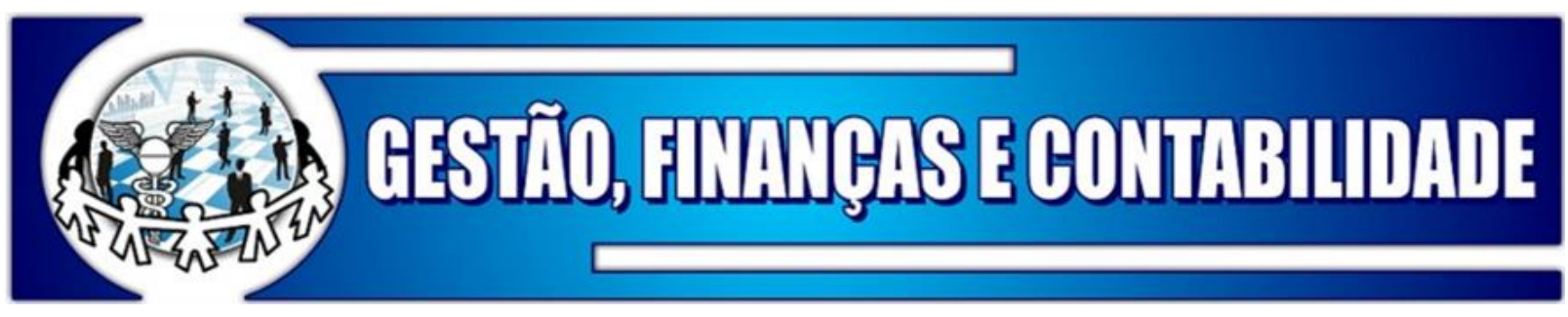

\title{
DETERMINANTES DA VIOLÊNCIA E CRIMINALIDADE NA BAHIA ENTRE OS ANOS DE 2015 A 2017
}

\author{
DETERMINANTS OF VIOLENCE AND CRIME IN \\ BAHIA BETWEEN THE YEARS 2015 TO 2017
}

\section{DETERMINANTES DE LA VIOLENCIA Y EL CRIMEN EN BAHÍA LOS AÑOS 2015 A 2017}

\begin{abstract}
Jadson Santana
https://orcid.org/0000-0001-8342-5378

Técnico da Coordenação de Estatística (Coest) da Superintendência de Estudos Econômicos e

Sociais da Bahia (SEI) Mestre em Administração pela Universidade Federal da Bahia

E-mail: jd.santanna@gmail.com

Alex Gama Queiroz dos Santos Técnico da Coordenação de Estatística (Coest) da Superintendência de Estudos Econômicos e Sociais da Bahia (SEI) Professor do curso de Ciências Econômicas da Universidade Salvador (Unifacs) Mestre em Economia pela Universidade Federal da Bahia

E-mail: alexgamaqs@gmail.com

Urandi Roberto Paiva Freitas

https://orcid.org/ 0000-0002-3370-9898 Coordenador da Coordenação de Estatística (Coest) da Superintendência de Estudos Econômicos e Sociais da Bahia (SEI) Mestre em Economia pela Universidade Federal da Bahia E-mail: urandipaiva@ hotmail.com
\end{abstract}

\section{RESUMO}

$\mathrm{Na}$ atualidade a Violência e Criminalidade constituem-se em graves problemas para a sociedade brasileira. No entanto, há uma percepção empírica de que esses fenômenos e sua tolerância variam consideravelmente entre as sociedades, comunidades e entre os indivíduos. O presente trabalho é uma análise dos fatores associados com a manifestação da Violência e Criminalidade na Bahia. Para tanto, foram construídos cinco cenários considerando diferentes proxys desses fenômenos e utilizada uma metodologia de Dados em Painel, com 4 modelos 


\title{
Determinantes da Violência e Criminalidade
}

na Bahia Entre os Anos de 2015 a 2017

econométricos e com informações dos 417 municípios do estado entre os anos de 2015 e 2017. Os principais resultados apontam que a estrutura social é um importante componente para a manifestação desses problemas sociais. Sendo assim, políticas de prevenção e combate à criminalidade devem considerar ações integradas entre os órgãos de justiça criminal e a família e a comunidade, subentendendo que estes são importantes propagadores de normas de conduta de coerção social.

Palavras-chave: Violência. Criminalidade. Bahia. Painel de Dados.

\begin{abstract}
Currently violence and crime are serious problems for Brazilian society. However, there is an empirical perception that these phenomena, and the tolerance to them, vary considerably among societies, communities and individuals. The present work is an analysis of the factors associated with the manifestation of violence and criminality in Bahia. To this end, five scenarios were built considering different proxies of these phenomena. A Panel Data methodology was used with 4 econometric models and information of the 417 municipalities of the state between the years 2015 to 2017 . The main results indicate that the social structure is an important component for the manifestation of these social problems. Therefore, policies to prevent and combat crime should consider integrated actions between criminal justice bodies and the family and the community, implying that they are important propagators of norms of conduct for social cohesion.
\end{abstract}

Keywords: Violence. Crime. Bahia. Data Panel.

\section{RESUMEN}

Actualmente, la Violencia y el Crimen son problemas graves para la sociedad brasileña. Sin embargo, existe una percepción empírica de que estos fenómenos y su tolerancia varían considerablemente entre sociedades, comunidades y entre individuos. El presente trabajo es un análisis de los factores asociados a la manifestación de la Violencia y Criminalidad en Bahía. Para ello, se construyeron cinco escenarios considerando diferentes proxies para estos fenómenos y se utilizó una metodología de Datos Panel com 4 modelos econométricos y información para los 417 municipios del estado entre los años 2015 y 2017. Los principales resultados indican que la estructura social es un componente importante para la manifestación de estos problemas sociales. Por tanto, las políticas de prevención y combate al delito deben considerar acciones integradas entre los órganos de justicia penal y la familia y la comunidad, implicando que son importantes propagadores de normas de conducta para la coacción social. Palabras llave: Violencia. Crimen. Bahia. Panel de datos.

\section{INTRODUÇÃO}

A violência é um fenômeno de natureza social e que se tornou um dos principais motes de debate da opinião e da arena política no Brasil contemporâneo. O ano de 2017 foi o mais violento de toda história brasileira pós-redemocratização. Ao todo foram 64,1 mil vítimas de Crimes Violentos Letais Intencionais (CVLI), o que representava uma taxa de 30,8 vítimas a cada 100 mil pessoas (ANUÁRIO BRASILEIRO DE SEGURANÇA PÚBLICA, 2019). Esses números colocavam o Brasil como um dos países mais violentos do mundo (WORLD HEALTH ORGANIZATION, 2019). E o espraiamento desse fenômeno ocorreu, sobretudo, nas regiões setentrionais, antes concentrado em grandes centros urbanos da Região

Revista de Gestão, Finanças e Contabilidade - v. 10, n. 2, p. 86-107, mai./ago. 2020 ISSN 2238-5320, UNEB, Salvador/BA 
Sudeste (NÓBREGA JR., 2016, 2017; KAHN, 2013).

Considerando a urgência dessa problemática, tem se ampliado o número de trabalhos que procuram investigar as causas da violência e criminalidade no Brasil (ERVILHA; LIMA, 2019; ANJOS JÚNIOR; LOMBARDI FILHO; AMARAL, 2018; CARRETS; OLIVEIRA; MENEZES, 2018; BECKER; KASSOUF, 2017). Uma grande parte desses estudos destaca os fatores de natureza socioeconômica como determinantes desse mal social. Tal fato é recorrente na literatura em que diversas contribuições teóricas podem ser utilizadas na investigação dessa problemática. Entre elas, vale destacar a Teoria Econômica do Crime, de caráter microssocial (BLOCK; HEINEKE, 1975; EHRLICH, 1973; BECKER, 1968) e a Teoria da Desorganização Social, de natureza macrossocial (SAMPSON; GROVES, 1989; SHAW; MCKAY, 1942). Utilizadas em conjunto, essas duas abordagens possibilitariam a combinação de fatores diversos que influem sobre a ação humana na geração de comportamentos desviantes (KELLY, 2000), ampliando o escopo de vetores para enfrentamento do problema pelo estado e pela sociedade.

Não obstante esses estudos tenham agregado ao debate científico sobre a temática, a manifestação da violência e criminalidade apresenta variabilidade conforme o contexto socioeconômico e temporal (CERQUEIRA, 2010; SOARES, 2008; CERQUEIRA; LOBÃO, 2003). Essa variabilidade ocorre devido à natureza do fenômeno estar estritamente relacionada à macroestrutura social e econômica. Havendo alterações no background socioeconômico, os vetores condicionantes tendem a apresentar variação em seu nível de influência na geração do fenômeno, ou até mesmo deixam de ser significativos em períodos subsequentes e em espaços diferentes. Essa constatação justifica a investigação empírica das causas da violência e criminalidade em diferentes realidades. E do ponto da ação pública, interessa saber em quais desses vetores o estado tem capacidade de intervir, a fim de desenvolver alternativas para mitigar os efeitos nocivos desse mal social.

Por sua vez, o estado da Bahia é um exemplo desse recrudescimento da violência e criminalidade no cenário nacional. Tal fato é confirmado pela escalada do fenômeno no estado entre os anos 2000 e 2010. Desde então, a Bahia passou a manter elevados índices de criminalidade, figurando entre os estados mais violentos do Brasil (ANUÁRIO BRASILEIRO DE SEGURANÇA PÚBLICA, 2019, 2011). Considerando apenas os anos de 2012 a 2017, o estado contabilizou 37,3 mil vítimas de CVLI. O incremento médio foi da ordem de 3,9\% ao ano. Apenas no ano de 2017 foram 6.328 vítimas de CVLI, o que representava 41,2 pessoas assassinadas a cada 100 mil habitantes (BAHIA, 2019). Sendo que, uma em cada quatro vítimas era um homem de 15 a 24 anos e a arma de fogo foi o instrumento utilizado em 75,0\% dos casos (BRASIL, 2019a). Entretanto, esse fenômeno não se concentrou apenas em cidades de médio e médio porte, mas se espalhou por outros municípios e regiões do estado (MANSO; DIAS; 2018). Tal problemática revela a importância da Bahia no contexto da violência brasileira, justificando sua relevância na investigação empírica do fenômeno.

Diante desse exposto, duas perguntas orientam a execução deste trabalho: Quais as causas da violência e criminalidade na Bahia? E ademais, em quais fatores o poder público tem possibilidade de intervir para mitigar os efeitos nocivos desse mal social? Isto posto, o objetivo desse trabalho é identificar os vetores socioeconômicos e estruturais que estão mais associados com a manifestação da violência e criminalidade na Bahia. Para tanto, utilizou-se uma metodologia econométrica de dados em painel com base em crimes diversos de 2015 a 2017 nos 417 municípios da Bahia. Partindo da premissa de que a violência é um fenômeno 


\section{Determinantes da Violência e Criminalidade}

na Bahia Entre os Anos de 2015 a 2017

multifacetado e a sua manifestação pode ocorrer em diferentes contextos, foram construídos cinco cenários em que são considerados variados aspectos do fenômeno a partir das variáveis a serem explicadas.

Além desta introdução, o trabalho está dividido em mais quatro partes: a próxima apresenta uma síntese dos aspectos conceituais e teóricos sobre a problemática; a terceira trata dos aspectos metodológicos; na penúltima são apresentados os resultados encontrados a partir da metodologia empregada e seguidos por uma discussão; e as principais considerações encerram o trabalho.

\section{VIOLÊNCIA E CRIMINALIDADE: UMA BREVE CONCEITUAÇÃO PARA ANÁLISE EMPÍRICA}

A conceituação de violência é amplamente discutida no campo teórico social e filosófico. E como um problema social, com dimensões relacionadas à saúde, ao desenvolvimento coletivo e à segurança, a violência e criminalidade podem ser investigadas por diversos enfoques acadêmicos, o que possibilita a ampliação do escopo de mecanismos para enfrentamento do problema pelo Estado e pela sociedade. No entanto, corriqueiramente se observam equívocos conceituais. Enquanto a violência envolve não somente a agressão física, mas todo tipo de ação em prejuízo a outrem (WORLD HEALTH ORGANIZATION, 2002), o crime é a caracterização ou qualificação de um ato ilegal, estritamente relacionado ao descumprimento de uma medida legalmente instituída. E por criminalidade, entende-se como o fenômeno social da prática criminosa, expressa em aspectos qualitativos e quantitativos.

A violência como objeto de estudo não foi inserida inicialmente na área de pesquisa social. Antes o foco eram as causas da criminalidade que estava inserido em matérias de direito penal e sociologia. A criminologia, então, emerge como estudo dos crimes e das suas causas. Na atualidade, no âmbito das ciências sociais, os estudos das causas da violência e da criminalidade seguem duas direções principais: i) estudos que focam na estrutura microssociológica em que são privilegiadas as características idiossincráticas e as motivações pessoais que direcionam o sujeito para o mundo do crime; e ii) trabalhos que destacam a estrutura macrossociológica e que consideram as variáveis processuais, estruturais e institucionais que incidem sobre o fenômeno (CANO; SOARES, 2002; CERQUEIRA; LOBÃO, 2003). E compreender a violência do ponto de vista socioeconômico, é entender como os aspectos desta natureza afetam na geração do fenômeno, conhecendo sua frequência e distribuição em grupos populacionais e identificando possíveis fatores de risco (PERES, 2004).

Nesse contexto, a associação entre a violência e criminalidade e os aspectos socioeconômicos tornou-se uma questão relevante em diversas abordagens teóricas e tem sido objeto de estudo em variados trabalhos (NÓBREGA JR., 2016, 2017; JUSTUS; KAHN; KAWAMURA, 2015; ADORNO, 2013; BEATO, 1998; COELHO, 1988; ZALUAR, 1993; 1985). No entanto, Kelly (2000) argumenta que na perspectiva social as teorias mais utilizadas e com alto poder de explicação dos fatores ligados a esses fenômenos são a Teoria Econômica do Crime e a Teoria da Desorganização Social.

O trabalho seminal de Becker (1968) inaugurou um ramo de estudos denominado de Teoria Econômica do Crime, a partir de um modelo teórico para analisar a criminalidade, violência e segurança pública sob a perspectiva econômica. Em linhas gerais, Becker (1968) trata da alocação ótima de recursos da sociedade com a finalidade de se obter o menor 
prejuízo possível dado certo padrão de penalidades, certa eficiência da polícia e do judiciário, bem como certa disposição das pessoas para cometerem ações criminosas, a qual dependeria dos dois fatores mencionados anteriormente e de uma série de características da sociedade, como nível de educação, nível de emprego e distribuição da renda (CLEMENTE, WALTERS, 2007).

Becker (1968) segue o paradigma marginalista, tendo como pressuposto que as pessoas agem sob o signo da racionalidade buscando obter, individualmente, o maior ganho possível. Nesse sentido, a partir de um cálculo estratégico, o indivíduo seria um ser racional tendo condições de escolher entre cometer um ato ilícito ou se envolver no mercado formal de trabalho, analisando as perdas e ganhos em ambos os contextos. Sendo assim, maiores oportunidades educacionais e profissionais teriam um efeito positivo na redução da criminalidade, pois o indivíduo optaria por se envolver no mercado formal de trabalho ao invés de adentrar na prática de atividades ilícitas. Dessa ação individual que se daria a oferta agregada de crimes, condicionada por determinados fatores da sociedade e a capacidade dissuasória do estado.

Não obstante a contribuição significativa de Becker (1968), o modelo original da Economia do Crime desconsidera a influência de importantes vetores sociais, estruturais e de natureza criminógena na ação individual. Ou seja, fatores macrossociais e que influiriam no comportamento criminoso não são considerados na sua análise, a exemplo de indivíduos que vivem em condições sociais e estruturais desvantajosas a quem não é dado a possibilidade de optar entre a formalidade ou informalidade. Isto porque, segundo Clemente e Walters (2007), a sociedade em que Becker (1968) se baseia para desenvolvimento do seu trabalho apresenta uma diferente estrutura macrossocial. Outros trabalhos acrescentaram à base teórica da Economia do Crime como Ehrlich (1973) e Block e Heineke (1975).

Contudo, uma questão relevante a partir de Becker (1968) é a transposição dos vetores teóricos em indicadores para operacionalização empírica. A ausência de pesquisas de vitimização ou a compilação de dados que apontem os perfis de perpetradores de crimes diversos, impossibilita a realização de análises de impactos dos vetores dissuasórios na oferta de crimes. Nesse sentido, os mais variados trabalhos que utilizam a teoria de Becker (1968) trabalham com indicadores agregados em nível regional, tendo como premissa o entendimento de que o indivíduo atua na região em que mora. Portanto, países, estados e municípios passam a ser a unidades de análise em estudos dessa natureza.

Por sua vez, a Teoria da Desorganização Social é o resultado de um estudo ecológico desenvolvido durante 20 anos por Shaw e McKay (1942) que investiga a relação entre a desorganização social de comunidades e o processo de crescimento de grandes cidades. Shaw e Mckay (1942) tomaram como base diferentes características de bairros em 21 cidades americanas para explicar a violência na estrutura interna das cidades. Os autores observaram uma relativa estabilidade do nível de crimes em determinados espaços durante o período analisado, embora tenha ocorrido uma completa mudança em termos étnicos e raciais.

Então, Shaw e McKay (1942) chegaram a conclusão de que deveria haver algum contexto social que influenciasse na manutenção da violência e criminalidade, além das características pessoais dos indivíduos. Segundo os autores, as áreas onde haviam problemas relacionados à infraestrutura urbana, baixo nível socioeconômico e elevada variação populacional, eram os locais onde as taxas de crimes e deliquência juvenil eram mais altas. Shaw e McKay (1942) identificaram também que as áreas de transição, com alto nível de 


\section{Determinantes da Violência e Criminalidade}

na Bahia Entre os Anos de 2015 a 2017

atratividade de imigrantes caracterizados por baixo nível de qualificação profissional e situação econômica, eram ambientes desorganizados socialmente e onde o exercício de controle social era ineficiente, resultando em uma elevada incidência da violência e da criminalidade. Portanto, de acordo com Shaw e McKay (1942), a violência e a criminalidade seriam desencadeadas pela menor integração social nas comunidades devido à ausência de mecanismos de auto-regulação, que por sua vez são produtos do impacto de fatores estruturais nas interações sociais.

Contudo, a partir dos anos 1950, a Teoria da Desorganização Social foi alvo de críticas substanciais, resultando em um abandono dos seus pressupostos. De acordo com Veysey e Messner (1999), essas críticas estavam voltadas para a utilidade e capacidade de interpretação do aporte teórico em nível macro, a estabilidade presumida nos padrões de utilização do espaço urbano e a medição da desorganização social como um constructo independente do resultado do empreendimento (SILVA; MARINHO, 2014). A Teoria da Desorganização Social voltou a receber atenção por parte dos pesquisadores em décadas recentes com o avanço e disponibilidade de instrumentos e técnicas estatísticas para se trabalhar com grandes bases de dados. $\mathrm{E}$ aliado a isso, novas metodologias e aprimoramento de outras abordagens teóricas complementares (SILVA; MARINHO, 2014). O primeiro trabalho empírico que testou os pressupostos da Teoria da Desorganização Social foi Sampson e Groves (1989). Os autores testaram o efeito mediador do que denominaram de dimensões componentes da desorganização social em relação às características estruturais da comunidade.

Utilizando uma base de dados extraída de um survey realizado na Grã-Bretanha, em 1982, com informações de 10.905 domicílios, Sampson e Groves (1989) chegaram à conclusão de que as características estruturais da comunidade, como urbanização e o grau de desestruturação familiar, afetam a capacidade de a comunidade impor controles formais e informais para os seus membros e pessoas externas em contato com o ambiente comunitário. Os autores demonstraram que a Teoria da Desorganização Social era de vital importância para explicar as variações dos níveis de crime e violência em nível macro-estrutural. Sampson e Groves (1989) aprimoraram o modelo teórico inicial da desorganização social acrescentando mais três variáveis: redes de amizades locais dispersas, grupos de adolescentes sem supervisão e baixa participação organizacional. Desde então, diversos estudos (CAIRES, 2017; JORGE, 2013) tem utilizado o poder explanatório da Teoria da Desorganização Social para explicar o crime e a violência em variados contextos urbanos.

Por sua vez, as estatísticas sobre violência e criminalidade, discutidas à luz da Sociologia e da Criminologia, podem auxiliar na compreensão dos conflitos sociais e como estes são processados e administrados pelo estado (LIMA; BORGES, 2014). Diversos crimes podem ser associados com o sentimento de instabilidade e insegurança que a violência provoca. Todavia, na perspectiva empírica para análise dessa problemática, o número de homicídios é a variável comumente associada à violência (NÓBREGA JR., 2017, 2016; JORGE, 2013; KHAN, 2013; SOARES FILHO, 2011). Uma das principais justificativas é o caráter de instabilidade social que o volume de homicídios pode resultar. E outro argumento favorável é que os registros de homicídios têm maior confiabilidade dos dados e uma maior disponibilidade comparada a outros eventos violentos.

As principais fontes dos dados de homicídios são: i) Declarações de Óbito (DO), na esfera das estatísticas vitais; e ii) Boletins de Ocorrência (BO), no âmbito da segurança 


\section{Determinantes da Violência e Criminalidade}

na Bahia Entre os Anos de 2015 a 2017

pública. O Estado Brasileiro tem como compulsório o registro de todos os óbitos ocorridos em território nacional (BRASIL, 1973). Os dados contidos nesses registros expõem os aspectos relacionados à morte do indivíduo e são utilizados pelo poder público para elaboração de políticas na área de saúde. No entanto, as estatísticas vitais têm sido largamente utilizadas para investigação das dinâmicas da violência e criminalidade por apresentar registros de mortes por agressões em um amplo horizonte temporal e com confiabilidade da informação (LIMA; BORGES, 2014).

Por outra via, os Boletins de Ocorrência (BO) são os registros dos eventos criminais sob a perspectiva legal. Os dados contidos nesses registros expõem todas as informações referentes ao crime ocorrido, como caracterização da vítima e autoria, motivação do ato delituoso, local de ocorrência, presença de fatores criminógenos e demais aspectos relacionados. Esses registros são coletados e geridos pelas secretarias de segurança pública no âmbito das administrações estaduais e são as principais fontes de dados criminais (BAHIA, 2019).

Para além dessas duas principais especificações, o termo Crime Violento Letal Intencional (CVLI) foi desenvolvido no contexto da segurança pública com o objetivo de ampliar a compreensão em torno da problemática e substituir o indicador antes comumente utilizado (homicídio). O CVLI tem sido largamente utilizado pela segurança pública no território nacional e é uma medida que visa agregar todos os tipos criminais que resultaram em mortes (homicídio doloso, latrocínio, lesão corporal seguida de morte e feminicídio), representando o total de vítimas fatais de agressão com intencionalidade definida (BRASIL, 2016; ANUÁRIO BRASILEIRO DE SEGURANÇA PÚBLICA, 2011).

Não obstante CVLI e os homicídios das estatísticas vitais indiquem um mesmo fim, existem divergências quanto à utilização destes entre os estudos de natureza acadêmica e os trabalhos técnicos na área da segurança pública. Contudo, do ponto de vista da compreensão da violência e criminalidade os dados de CVLI são os registros ideais, pois informam os aspectos relacionados à ocorrência do ato delituoso. Porém, a indisponibilidade desses dados em diversas unidades da federação e a ausência de uma série histórica confiável direcionam os interessados a utilizar os registros de homicídios das estatísticas vitais. E é a partir desses dados que se constroem indicadores para mensurar os impactos da criminalidade e violência em um determinado espaço geográfico e para um período de tempo específico.

\section{ASPECTOS METODOLÓGICOS: CENÁRIOS E METODOLOGIA DE DADOS EM PAINEL}

A metodologia utilizada é uma modelagem econométrica para dados em painel. Por se tratar de um fenômeno multifacetado não há possibilidade de mensurar todos os fatores determinantes, considerando que há uma realidade não-observável. Por isso, essa metodologia é a mais adequada porque controla a heterogeneidade não-observável (HOLTZ-EAKIN; NEWEY; ROSEN, 1998), já que acompanha uma mesma unidade (neste caso, as unidades de análise são os 417 municípios baianos) ao longo do tempo (anos de 2015 a 2017) e oferece importantes ganhos de informação devido o emprego conjunto de informação temporal e entre os grupos. 2010):

Um modelo geral de dados em painel pode ser representado por (WOOLDRIDGE,

$$
y_{i t}=\beta_{0 i t}+\beta_{1 i t}+x_{1 i t}+\ldots+\beta_{n i t}+x_{k i t}+e_{i t}
$$

Revista de Gestão, Finanças e Contabilidade - v. 10, n. 2, p. 86-107, mai./ago. 2020 ISSN 2238-5320, UNEB, Salvador/BA 


\section{Determinantes da Violência e Criminalidade}

na Bahia Entre os Anos de 2015 a 2017

onde:

$i=$ denota os diferentes indivíduos

$t=$ período de tempo que está sendo analisado

$\beta_{0}=$ refere-se ao parâmetro do intercepto

$\beta_{K}=$ refere-se ao coeficiente angular correspondente à k-enésima variável explicativa do modelo

$e=$ erro estocástico

Para maior compreensão do fenômeno foram construídos 5 cenários em que foram consideradas variáveis dependentes como proxys da violência e criminalidade. O Quadro 1 sumariza os cenários, variáveis e referências. Para os 4 primeiros foi construído um modelo econométrico de Dados em Painel com as variáveis explicativas (Quadro 2). E para o Cenário 5 , foram replicados os quatro primeiros modelos.

Quadro 1 - Cenários e variáveis dependentes

\begin{tabular}{|c|c|c|c|c|}
\hline Cenários & Conceito & Variável & Referência & Fonte \\
\hline Cenário 1 & CVLI & $\begin{array}{l}\text { Somatório do número } \\
\text { CVLI }\end{array}$ & $\begin{array}{l}\text { Brasil (2016); Anuário } \\
\text { Brasileiro de Segurança } \\
\text { Pública (2011). }\end{array}$ & $\begin{array}{l}\text { Secretaria da } \\
\text { Segurança Pública } \\
\text { (BAHIA, 2019) }\end{array}$ \\
\hline Cenário 2 & Homicídios & $\begin{array}{l}\text { Somatório do número } \\
\text { de homicídios }\end{array}$ & $\begin{array}{c}\text { Brasil (2019a); OMS } \\
\text { (1994) }\end{array}$ & Brasil (2019a) \\
\hline Cenário 3 & $\begin{array}{l}\text { Crimes contra } \\
\text { patrimônio }\end{array}$ & $\begin{array}{l}\text { Somatório do número } \\
\text { de furtos e roubo de } \\
\text { veículos }\end{array}$ & Carrets et. al. (2018) & $\begin{array}{l}\text { Secretaria da } \\
\text { Segurança Pública } \\
\text { (BAHIA, 2019) }\end{array}$ \\
\hline Cenário 4 & $\begin{array}{l}\text { Homicídios de homens } \\
\text { jovens }\end{array}$ & $\begin{array}{c}\text { Número de mortes por } \\
\text { agressões de homens de } \\
15 \text { a } 24 \text { anos }\end{array}$ & $\begin{array}{l}\text { Andrade; Lisboa (2002); } \\
\text { Jorge (2013); Ferreira et. } \\
\text { al. (2016). }\end{array}$ & Brasil (2019) \\
\hline Cenário 5 & $\begin{array}{c}\text { Crimes Diversos - } \\
\text { Planesp } 40 \text { municípios }\end{array}$ & Diversos & Planesp (BAHIA, 2017) & $\begin{array}{l}\text { Secretaria da } \\
\text { Segurança Pública } \\
\text { (BAHIA, 2019) }\end{array}$ \\
\hline
\end{tabular}




\section{Determinantes da Violência e Criminalidade}

na Bahia Entre os Anos de 2015 a 2017

Fonte: Elaboração própria.

Os dois primeiros cenários procuram investigar os padrões por trás das ocorrências de CVLI e homicídios e apontar qual é a proxy mais adequada para mensurar a violência e criminalidade. No Cenário 3 são considerados os crimes de natureza patrimonial e a associação destes com as variáveis explicativas. Objetiva-se investigar se há alguma alteração de padrão entre a ocorrência destes em comparação aos cenários anteriores. $\mathrm{O}$ Cenário 4 procura explicações para os homicídios de homens jovens, sendo utilizadas apenas variáveis que tenham relação direta com a variável a ser explicada. O Cenário 5 analisa todas as questões anteriores para os 40 municípios prioritários do Planesp 2016-2025 (BAHIA, 2017). A justificativa é que esses municípios concentram em torno de 70,0\% dos casos de CVLI do estado entre os anos de 2012 e 2017 (BAHIA, 2019). Vale destacar que, todos os 17 municípios da Bahia com mais de 100 mil habitantes estão nesse grupo de prioritários. Além de mais populosos, estes eram os municípios que apresentavam elevado nível de urbanização e renda média no estado (SEI, 2018), o que pode indicar alguma associação com a ocorrência de crimes diversos.

Por sua vez, as variáveis explicativas foram selecionadas considerando: 1) adequação às abordagens teóricas da Economia do Crime e Desorganização Social; e 2) disponibilidade de dados a nível municipal. O Quadro 2 apresenta as dimensões utilizadas, descrição das variáveis, referência, fonte de dados e o impacto esperado.

Foram consideradas dezesseis variáveis explicativas dividias em quatro dimensões: i) educação; ii) desorganização social; iii) econômicas; iv) categóricas. Para o primeiro bloco, diversas expectativas teóricas (CERQUEIRA et al., 2016; SANTOS, 2009; BUONANNO; LEONIDA, 2005) apontam para o efeito virtuoso que a educação tem na redução da criminalidade e violência. No segundo agrupamento destacam-se variáveis associadas ao constructo da Desorganização Social, cujo objetivo é investigar a relação da desestruturação do tecido social para a manifestação de crimes diversos (CAIRES, 2017; SANTANA, 2018).

Para o terceiro bloco foram consideradas variáveis relacionadas a uma maior disponibilidade de recursos para reprodução social, o que teria efeitos contraditórios a depender do contexto em que estejam inseridas (ARAÚJO JR., 2002; CRUZ; ARAÚJO, 2012). E no último bloco foram utilizadas variáveis categóricas que apontam aspectos, sobretudo, estruturais e locacionais (CAIRES, 2017).

$\mathrm{Na}$ operacionalização todas as variáveis foram transformadas em logaritmos $(\log )$, exceto as que eram taxas e as de natureza categórica. Como é padrão em estudos criminométricos, utilizam-se os $\log s$ de todas as variáveis para estimar as elasticidades (CORNWELL; THUMBULL, 1994). Nesses casos, os coeficientes obtidos representam as elasticidades em relação à variável desse coeficiente, ou seja, o aumento de 1,0 p.p na referida variável resultaria no impacto do fenômeno apresentado pelo regressor. Os modelos foram estimados em duas técnicas diferentes: Efeito Fixo e Efeito Aleatório. Para os 4 primeiros modelos a estimação em efeitos fixos mostrou-se mais adequada. Enquanto que no Cenário 5, o efeito aleatório. E o software utilizado para estimação foi Eviews 8.0 e para estruturação das tabelas o Microsoft Excel.

Quadro 2 - Variáveis explicativas

\begin{tabular}{|c|c|c|c|c|c|}
\hline Dimensão & Conceito & Variável & Referência & Fonte & $\begin{array}{l}\text { Impacto } \\
\text { esperado }\end{array}$ \\
\hline
\end{tabular}


Santana, Santos e Freitas (2020)

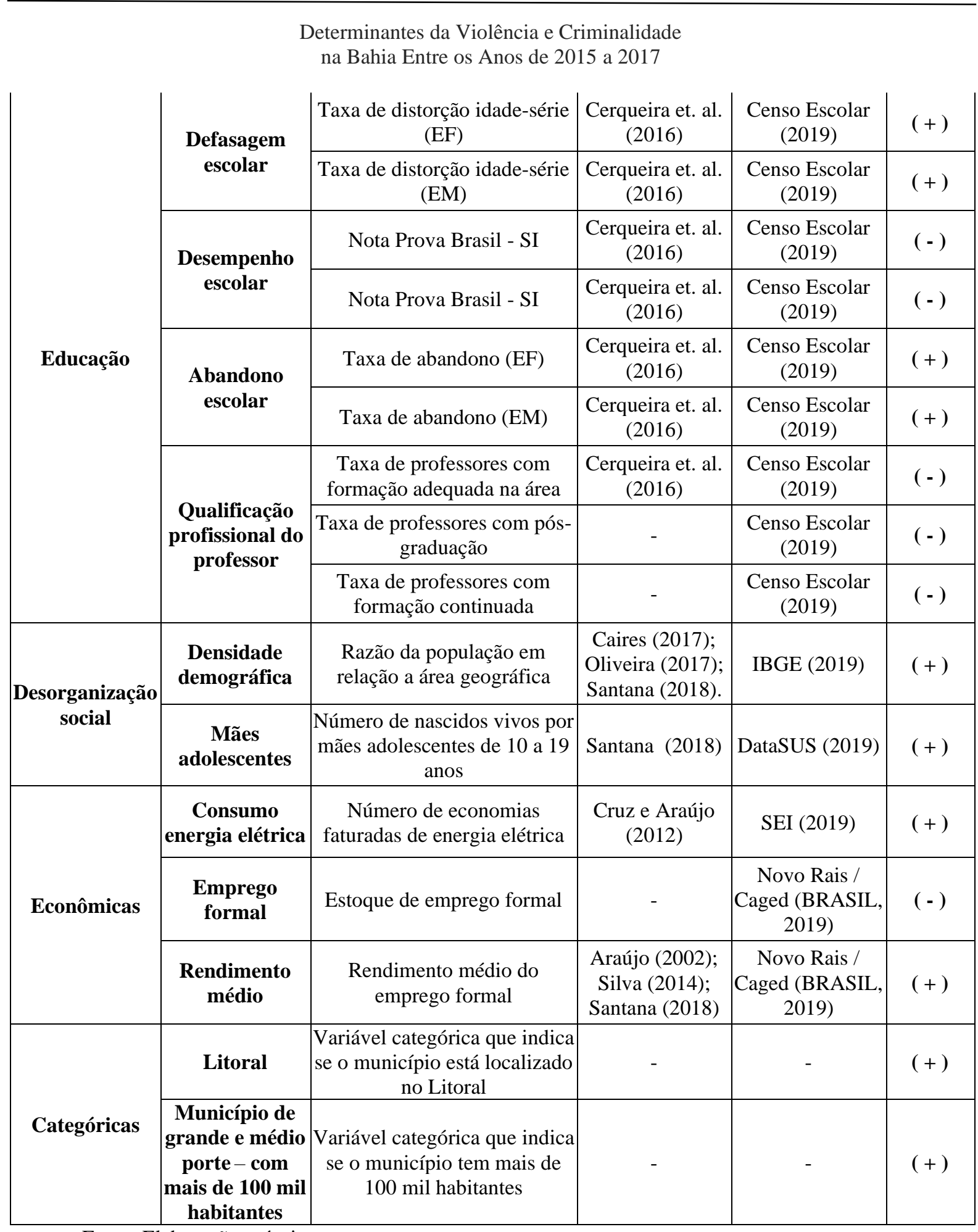

Fonte: Elaboração própria.

Nota: $\mathrm{EF}$ = Ensino Fundamental; EM = Ensino Médio; SI: Séries Iniciais; SF=Séries Finais

\section{RESULTADOS E DISCUSSÃO}

Os resultados das estimações são apresentados a seguir. Para cada variável explicativa constam dois valores: acima o coeficiente de regressão - indica que dado o aumento de 1,0 p.p. da referida variável, qual seria o impacto no fenômeno; e abaixo o P-valor - aponta o 


\section{Determinantes da Violência e Criminalidade} na Bahia Entre os Anos de 2015 a 2017

nível de significância da associação entre a variável explicativa e a variável dependente. Variáveis estatisticamente significativas a um nível de 10,0\% (P-valor menor que 0,1) foram destacadas das demais. E o sinal do regressor indica a relação da variável com o fenômeno: sinal negativo aponta relação inversa, enquanto que a ausência de sinal indica uma relação positiva.

É apresentado também o coeficiente de determinação $\mathrm{R}^{2}$, que é uma medida de ajustamento do modelo de regressão e que varia entre 0 (zero) e 1 (um) e indica, em termos percentuais, o quanto o modelo consegue explicar dos valores observados. E por fim a estatística $d$ de Durbin-Watson que detecta a presença de auto-correlação nos resíduos da análise de regressão (GUJARATI, 2009). Antes das estimações, realizou-se uma análise de correlação com o objetivo de identificar as variáveis independentes que estavam mais fortemente relacionadas, não sendo necessário fazer ajustes com a retirada de variáveis.

Tabela 1 - Resultados das estimações dos Cenários 1 a 4

\begin{tabular}{|c|c|c|c|c|c|c|}
\hline \multicolumn{3}{|c|}{ Variável } & Cenário 1 & Cenário 2 & Cenário 3 & Cenário 4 \\
\hline \multirow{26}{*}{ Educação } & \multirow{8}{*}{ Abandono escolar } & \multirow{2}{*}{ Abandono escolar - EF } & 0,0086 & 0,0077 & $-0,0098$ & \\
\hline & & & $(0,4272)$ & $(0,5214)$ & $(0,4815)$ & \\
\hline & & \multirow{2}{*}{ Abandono escolar - EF / SI } & & & & $-0,0074$ \\
\hline & & & & & & $(0,7242)$ \\
\hline & & \multirow{2}{*}{ Abandono escolar - EF / SF } & & & & 0,0061 \\
\hline & & & & & & $(0,5289)$ \\
\hline & & \multirow{2}{*}{ Abandono escolar - EM } & 0,0019 & 0,0030 & $-0,0006$ & 0,0115 \\
\hline & & & $(0,6784)$ & $(0,5609)$ & $(0,9172)$ & $(0,0534)$ \\
\hline & \multirow{4}{*}{$\begin{array}{l}\text { Desempenho } \\
\text { escolar }\end{array}$} & \multirow{2}{*}{$\begin{array}{l}\text { Qualidade da educação - EF } \\
\text { / SI }\end{array}$} & $-0,0971$ & $-0,4944$ & $-0,0694$ & $-0,3697$ \\
\hline & & & $(0,0046)$ & $(0,0659)$ & $(0,0658)$ & $(0,2678)$ \\
\hline & & \multirow{2}{*}{$\begin{array}{l}\text { Qualidade da educação - EF } \\
\text { / SF }\end{array}$} & 0,0392 & $-0,2461$ & $-0,0086$ & $-0,5816$ \\
\hline & & & $(0,1638)$ & $(0,2088)$ & $(0,8072)$ & $(0,0145)$ \\
\hline & \multirow{8}{*}{ Defasagem escolar } & \multirow{2}{*}{ Distorção idade $\mathrm{x}$ série - EF } & 0,0086 & 0,0044 & 0,0048 & \\
\hline & & & $(0,0773)$ & $(0,4175)$ & $(0,4467)$ & \\
\hline & & \multirow{2}{*}{$\begin{array}{l}\text { Distorção idade x série - EF } \\
\text { / SI }\end{array}$} & & & & 0,0224 \\
\hline & & & & & & $(0,0010)$ \\
\hline & & \multirow{2}{*}{$\begin{array}{l}\text { Distorção idade x série - EF } \\
\text { / SF }\end{array}$} & & & & $-0,0156$ \\
\hline & & & & & & $(0,0097)$ \\
\hline & & \multirow{2}{*}{$\begin{array}{l}\text { Distorção idade x série - } \\
\text { EM }\end{array}$} & 0,0080 & $\mathbf{0 , 0 1 3 3}$ & $-0,0011$ & 0,0111 \\
\hline & & & $(0,0232)$ & $(0,0006)$ & $(0,8050)$ & $(0,0156)$ \\
\hline & \multirow{6}{*}{$\begin{array}{c}\text { Qualificação } \\
\text { profissional do } \\
\text { professor }\end{array}$} & \multirow{2}{*}{$\begin{array}{l}\text { Formação continuada do } \\
\text { professor }\end{array}$} & 0,0026 & 0,0023 & 0,0017 & 0,0063 \\
\hline & & & $(0,1732)$ & $(0,2830)$ & $(0,5014)$ & $(0,0137)$ \\
\hline & & \multirow{2}{*}{$\begin{array}{l}\text { Formação adequada do } \\
\text { professor }\end{array}$} & 0,0056 & 0,0050 & $\mathbf{0 , 0 1 7 0}$ & 0,0101 \\
\hline & & & $(0,1829)$ & $(0,2772)$ & $(0,0020)$ & $(0,0692)$ \\
\hline & & \multirow{2}{*}{$\begin{array}{l}\text { Professores com pós- } \\
\text { graduação }\end{array}$} & 0,0022 & 0,0049 & 0,0025 & 0,0019 \\
\hline & & & $(0,3880)$ & $(0,0797)$ & $(0,4504)$ & $(0,5555)$ \\
\hline \multirow{4}{*}{\multicolumn{2}{|c|}{ Desorganização social }} & \multirow{2}{*}{ Mães adolescentes } & 0,4863 & 0,4463 & 0,3694 & \\
\hline & & & $(0,0000)$ & $(0,0000)$ & $(0,0000)$ & \\
\hline & & \multirow{2}{*}{ Densidade demográfica } & 0,0000 & 0,0001 & 0,0003 & \\
\hline & & & $(0,8416)$ & $(0,5838)$ & $(0,0262)$ & \\
\hline
\end{tabular}

Revista de Gestão, Finanças e Contabilidade - v. 10, n. 2, p. 86-107, mai./ago. 2020 ISSN 2238-5320, UNEB, Salvador/BA 
Santana, Santos e Freitas (2020)

Determinantes da Violência e Criminalidade

na Bahia Entre os Anos de 2015 a 2017

\begin{tabular}{|c|c|c|c|c|c|}
\hline \multirow{6}{*}{ Econômicas } & \multirow{2}{*}{ Emprego formal } & 0,3159 & 0,2678 & 0,3421 & 0,3990 \\
\hline & & $(0,0000)$ & $(0,0000)$ & $(0,0000)$ & $(0,0000)$ \\
\hline & \multirow{2}{*}{ Consumo energia elétrica } & 0,1526 & 0,2390 & 0,2777 & \\
\hline & & $(0,0136)$ & $(0,0005)$ & $(\mathbf{0 , 0 0 0 3 )}$ & \\
\hline & \multirow{2}{*}{ Rendimento } & 0,0997 & 0,1633 & 0,2263 & 0,4279 \\
\hline & & $(0,3494)$ & $(0,1740)$ & $(0,0924)$ & $(0,0315)$ \\
\hline \multirow{4}{*}{ Categóricas } & \multirow{2}{*}{$\begin{array}{l}\text { Município de grande e } \\
\text { médio porte }\end{array}$} & 0,3142 & 0,3859 & 0,5505 & 1,3630 \\
\hline & & $(0,0668)$ & $(0,0348)$ & $(0,0198)$ & $(0,0000)$ \\
\hline & \multirow{2}{*}{ Litoral } & 0,3551 & 0,3749 & $-0,3901$ & \\
\hline & & $(0,0009)$ & $(0,0010)$ & $(0,0091)$ & \\
\hline \multirow{2}{*}{\multicolumn{2}{|c|}{ Constante }} & $-6,3933$ & $-7,0582$ & $-8,0008$ & $-3,3426$ \\
\hline & & 0,0000 & 0,0000 & 0,0000 & $(0,0202)$ \\
\hline \multicolumn{2}{|c|}{ Número de observações } & 1.101 & 1.045 & 1.103 & 781 \\
\hline \multicolumn{2}{|c|}{$\mathbf{R}^{2}$} & 0,5885 & 0,5725 & 0,4757 & 0,5102 \\
\hline \multicolumn{2}{|c|}{ Durbin-Watson } & 1,9957 & 1,8646 & 1,8820 & 1,8375 \\
\hline
\end{tabular}

Fonte: Elaboração própria.

O modelo do Cenário 1 conseguiu explicar, aproximadamente, 59,0\% da variabilidade dos casos de CVLI no estado. Nove entre dezesseis mostraram-se significativas. Contudo, importantes vetores na dimensão educação não apresentaram associação. Os resultados indicam que o abandono escolar não é um fator relevante, o que contradiz expectativas teóricas (CERQUEIRA et al., 2016). No vetor qualidade da educação apenas o desempenho das Séries Iniciais apresentou associação com o fenômeno. Destaca-se que esse nível escolar engloba as crianças de 6 a 10 anos, grupo social que não compõe as principais vítimas de mortes violentas (BRASIL, 2019a; WAISELFISZ, 2016). E o bom desempenho dos alunos nessa faixa etária pode estar mais relacionado ao ambiente familiar e a influência dos pais (especialmente o nível de formação da mãe) do que a qualidade do ensino ofertado (MENEZES FILHO, 2007).

$\mathrm{Na}$ defasagem escolar as variáveis apresentaram associação com o fenômeno, porém com reduzidos regressores. Surpreendentemente os resultados para o Cenário 1 apontam que o aperfeiçoamento docente não tem relação com a ocorrência de CVLIs, o que contradiz as proposições que argumentam em favor da qualificação dos professores por pressupor uma melhora direta na qualidade do serviço ofertado (CERQUEIRA et. al., 2016). Contudo, isto não significa que esse seja um vetor dispensável, mas pode indicar que outros fatores como a didática, esforço e preparação docente não foram observados (MENEZES FILHO, 2007; HANUSHEK; RIVKIN, 2006). Outro aspecto que pode ser investigado em conjunto com esse vetor é a estrutura da escola em que o professor atua.

Na dimensão desorganização social, a variável mães adolescentes destacou-se entre as demais. Estudos apontam que esse é um fator relacionado a diversos elementos que caracterizam ambientes socialmente desorganizados, tais como baixo nível socioeconômico, consumo de álcool e drogas, início precoce de relações sexuais e o não-uso (ou uso inadequado) de métodos contraceptivos (FARIAS; MORÉ, 2012; LEVANDOWSKI; PICCININI; LOPES, 2008). Contudo, é importante destacar que não se trata de uma afirmação de que as mães adolescentes são responsáveis pelo nível de violência e criminalidade, mas um indicativo de um ambiente socialmente desorganizado.

$\mathrm{Na}$ dimensão econômica, apenas o rendimento médio não foi significativo. Os demais

Revista de Gestão, Finanças e Contabilidade - v. 10, n. 2, p. 86-107, mai./ago. 2020 ISSN 2238-5320, UNEB, Salvador/BA 


\section{Determinantes da Violência e Criminalidade}

na Bahia Entre os Anos de 2015 a 2017

vetores tiveram resultados esperados: emprego formal (0,3159); consumo de energia elétrica $(0,1526)$. Esse último supõe que o consumo de energia elétrica seria uma proxy alternativa para mensurar o nível de consumo. E para as variáveis categóricas ambas apresentaram significância. Isso indica que o fato do município estar localizado no litoral ou ser de grande ou médio porte, tem maior propensão na ocorrência de casos de CVLI. Os demais vetores que teriam relação com o fenômeno estariam entre os fatores não observados.

Para o Cenário 2 os principais resultados são similares aos encontrados no Cenário 1. As mortes por agressão têm motivações sociais próximas as dos CVLIs, diferindo apenas na origem dos dados. Comparando os resultados dos dois primeiros cenários, observa-se que no primeiro as variáveis independentes tinham maior capacidade de explicação. Essa observação pode apontar para os registros de CVLI como uma medida mais adequada para mensurar a violência e criminalidade. Contudo, outras análises devem ser realizadas considerando essa comparação: estatísticas criminais versus as estatísticas vitais.

O modelo do Cenário 3 conseguiu explicar $47,6 \%$ dos casos de crimes patrimoniais no estado. Contudo, observa-se um padrão diverso dos anteriores, o que pode estar associado à natureza desses crimes, associada, sobretudo, à motivação econômica (BEATO, 1998). Na dimensão educação apenas o desempenho da educação básica para as séries iniciais destacouse entre as demais. Não obstante seja um impacto reduzido, vale salientar que esse mesmo comportamento foi observado nos cenários anteriores, o que pode denotar um importante componente para enfrentamento da violência e criminalidade. As demais variáveis de educação não tinham qualquer relação com a ocorrência de crimes patrimoniais, o que pode indicar que os delitos dessa natureza seriam cometidos por indivíduos que estão fora do círculo de influência da educação básica.

No grupo de variáveis econômicas todas apresentaram associação positiva com o fenômeno. E para o último grupo, ambas variáveis mantiveram a associação observada nos cenários anteriores. Contudo, o fato do município estar localizado no litoral apresentou resultado contrário do esperado, ou seja, a ocorrência de crimes de natureza material independe de o município estar ou não na faixa litorânea, fato este que não foi observado nos casos de CVLI e homicídios. Por fim, os crimes patrimoniais mostraram ser um fenômeno de natureza urbana, conforme observado no resultado do regressor para a variável que aponta os municípios de grande ou médio porte.

O modelo do Cenário 4 conseguiu explicar 51,0\% da variabilidade dos casos de homicídios de homens jovens na Bahia. Contudo, os resultados divergem dos observados anteriormente, inclusive para o segundo cenário em que a variável dependente é o número de homicídios. A dimensão educação assume um papel preponderante. No primeiro vetor, destaca-se o abandono escolar no Ensino Médio, único com resultado significativo. Isso pode indicar que o fato do adolescente abandonar a escola tem associação direta com o incremento dos homicídios de homens jovens. Sendo assim, a manutenção do adolescente no ambiente escolar é uma ação que deve ser analisada em especial. Por sua vez, no que concerne ao desempenho escolar apenas o desempenho dos alunos das séries finais do ensino fundamental (que engloba a faixa etária de 11 a 14 anos) apresentou significância e com elevado regressor quando comparado a outros elementos.

Todas as variáveis do vetor distorção escolar eram significativas. Contudo, nem todas com os sinais esperados. Porém, as distorções idade-série para os anos iniciais e o Ensino Médio apresentaram resultados satisfatórios. Novamente o componente associado ao Ensino 
Médio destacou-se. Sendo assim, propostas de políticas públicas para enfrentamento da violência deve considerar a atração e permanência dos adolescentes no ambiente escolar como elementos primordiais. Outros componentes educacionais como oferta de vagas em tempo integral, estrutura e o ambiente escolar, bem como a existência de atividades complementares, devem ser considerados em análises futuras a fim de aumentar a atratividade e permanência dos adolescentes na escola.

Entre as variáveis econômicas, tanto o emprego formal quanto o rendimento médio, apresentaram significância. Esses resultados apontam para uma direção contrária do que a teoria fundamenta: o caráter dissuasório desses elementos (BECKER, 1968). Sendo assim, no contexto baiano, a oferta de trabalhos e ganhos de salário não seriam mecanismos de efeitos imediatos para reduzir o número de mortes violentas de homens jovens. Sobre essa observação deve-se considerar um aspecto importante. Boa parte das mortes de homens jovens pode estar relacionada às diversas disputas entre facções criminosas para controle do comércio de drogas ilícitas. E a falta de credibilidade no poder público devido à ausência de ações sociais e a precariedade das estruturas dos serviços públicos, faz com que uma grande parte desses jovens deixe de acreditar no estado como solucionador de suas demandas pessoais. Automaticamente, os mecanismos convencionais para atratividade do jovem, como oportunidades de empregos e aumento de renda, deixariam de ser interessantes para esse grupo social, pois não mais acreditariam que a sociedade (por meio de um estado atuante) teria capacidade de recuperá-los do mundo do crime.

Do ponto de vista da intervenção pública, esses resultados apontam para dois caminhos. $\mathrm{O}$ primeiro diz respeito aos mecanismos que o estado pode utilizar para retirar os jovens da criminalidade, já que uma parte dos instrumentos convencionais não surtiria o efeito desejado. E o segundo aponta para a idade em que esses jovens entram para a prática delituosa, sendo esse o limiar para atuação do poder público impedindo com que mais indivíduos desse grupo social adentrassem na vida criminosa.

Para o Cenário 5 (Tabela 2) observaram-se alterações consideráveis. Essas mudanças indicam que os contextos socioeconômicos têm grande influência na geração da violência e criminalidade, apontando para diferentes tipos de ações na prevenção e enfrentamento desse problema social, variando conforme o nível de estrutura social e econômica do município, região, estado e país (BEATO, 1998; COHEN; FELSON, 1979).

$\mathrm{Na}$ primeira estimação (CVLI como variável dependente), observou-se que nove vetores apresentaram relação com o fenômeno. Na dimensão educação, o abandono escolar novamente não se mostrou significativo. Contudo, a qualidade da educação das séries finais apresentou resultados consistentes. Ainda na dimensão educação, a defasagem escolar das séries finais apresentou resultados esperados, porém com baixo nível de associação. E a qualificação docente teve resultados contraditórios para as três variáveis observadas, não sendo possível concluir que esse vetor tem significância. Nas demais dimensões, mães adolescentes destacou-se dentre as outras variáveis, evidenciando novamente o constructo da desorganização social. Emprego formal e rendimento médio mostraram-se significativos.

$\mathrm{Na}$ segunda análise (número de homicídios), observa-se outra variação tanto para o Cenário 2, quanto para a primeira análise do quinto cenário. Do total de variáveis explicativas, apenas cinco foram significativas, entre elas mães adolescentes (com elevado valor do regressor) e a qualidade da educação das séries finais. Contudo, destaca-se que surpreendentemente nenhuma variável do vetor econômico e categóricas eram significativas 
estatisticamente. Comparando os modelos, o primeiro conseguiu explicar 90,9\% da variabilidade dos casos de CVLI nos 40 municípios prioritários, contra 71,2\% do segundo modelo. Novamente o registro de CVLI mostrou-se mais adequado para mensurar a criminalidade e violência no contexto baiano.

$\mathrm{Na}$ terceira estimação, observa-se outra mudança que está em conformidade com observado para o Cenário 3. Surpreendentemente, o número de mães adolescentes não se mostrou significativo, único cenário em que essa variável não apresentou significância. Rendimento médio e emprego formal sustentaram a mesma relação observada na regressão anterior. Destaca-se que ambas tinham um elevado nível de associação, o que ratifica o fato de variáveis de caráter econômico funcionarem como um gatilho para a ocorrência de crimes dessa natureza. Os crimes patrimoniais que ocorreram nos municípios prioritários do Planesp 2016-2025 foram associados a quatro variáveis, do total de dezesseis disponíveis.

$\mathrm{Na}$ última análise a principal observação é uma mudança substancial entre esses resultados e os observados no Cenário 4. Das variáveis explicativas apenas quatro apresentaram associação com o fenômeno. $\mathrm{Na}$ dimensão educação o desempenho escolar das séries finais apresentou resultado significativo. Ou seja, no caso dos municípios prioritários, ações de enfrentamento a violência e criminalidade devem considerar o limiar entre 14 e 15 anos. Na primeira idade, está o grupo social que se encontra nas séries finais do ensino fundamental, fator determinante neste cenário. E a segunda é o limítrofe no incremento de homicídios da população jovem. Propostas de políticas públicas devem ser atrativas a esse grupo social para mantê-los no ambiente escolar antes que sejam aliciados para o mundo do crime.

Por fim, um comparativo entre os Cenário 1 a 4 e o Cenário 5, aponta que as estruturas macrossociais têm um peso relevante para a ocorrência de diversos crimes, ratificado pela alteração de significância em diversas variáveis. Sendo assim, a associação entre as variáveis macroestruturais e a criminalidade varia de acordo com o contexto.

Tabela 2 - Resultados das estimações do Cenário 5

\begin{tabular}{|c|c|c|c|c|c|c|}
\hline \multicolumn{3}{|c|}{ Variável } & Análise 1 & Análise 2 & Análise 3 & Análise 4 \\
\hline \multirow{5}{*}{ Educação } & \multirow{5}{*}{$\begin{array}{l}\text { Abandono } \\
\text { escolar }\end{array}$} & \multirow{2}{*}{ Abandono escolar - EF } & 0,0172 & 0,0688 & $-0,0073$ & \\
\hline & & & $(0,5541)$ & $(0,2847)$ & $(0,8924)$ & \\
\hline & & \multirow{2}{*}{$\begin{array}{l}\text { Abandono escolar - EF / } \\
\text { SI } \\
\end{array}$} & & & & 0,0670 \\
\hline & & & & & & $(0,4437)$ \\
\hline & & Abandono escolar - EF / & & & & 0,0320 \\
\hline
\end{tabular}


Santana, Santos e Freitas (2020)

Determinantes da Violência e Criminalidade na Bahia Entre os Anos de 2015 a 2017

\begin{tabular}{|c|c|c|c|c|c|}
\hline & $\mathrm{SF}$ & & & & $(0,4263)$ \\
\hline & \multirow{2}{*}{ Abandono escolar - EM } & 0,0045 & 0,0068 & $-0,0250$ & 0,0294 \\
\hline & & $(0,6957)$ & $(0,7895)$ & $(0,2445)$ & $(0,2489)$ \\
\hline \multirow{4}{*}{$\begin{array}{l}\text { Desempenho } \\
\text { escolar }\end{array}$} & \multirow{2}{*}{$\begin{array}{l}\text { Qualidade da educação - } \\
\text { EF / SI }\end{array}$} & 0,2437 & $-0,0728$ & 0,1048 & 0,2321 \\
\hline & & $(0,0937)$ & $(0,8195)$ & $(0,6955)$ & $(0,4507)$ \\
\hline & \multirow{2}{*}{$\begin{array}{l}\text { Qualidade da educação - } \\
\text { EF / SF }\end{array}$} & $-0,2980$ & $-0,9096$ & 0,0148 & $-0,9204$ \\
\hline & & $(0,0180)$ & $(0,0012)$ & $(0,9487)$ & $(0,0005)$ \\
\hline \multirow{8}{*}{$\begin{array}{l}\text { Defasagem } \\
\text { escolar }\end{array}$} & \multirow{2}{*}{$\begin{array}{l}\text { Distorção idade x série - } \\
\text { EF }\end{array}$} & 0,0025 & $-0,0046$ & 0,0201 & \\
\hline & & $(0,7329)$ & $(0,7755)$ & $(0,1359)$ & \\
\hline & \multirow{2}{*}{$\begin{array}{l}\text { Distorção idade x série - } \\
\text { EF / SI }\end{array}$} & & & & 0,0066 \\
\hline & & & & & $(0,7463)$ \\
\hline & \multirow{2}{*}{$\begin{array}{l}\text { Distorção idade x série - } \\
\text { EF / SI }\end{array}$} & & & & 0,0021 \\
\hline & & & & & $(0,9084)$ \\
\hline & \multirow{2}{*}{$\begin{array}{l}\text { Distorção idade x série - } \\
\text { EM }\end{array}$} & 0,0202 & 0,0202 & $-0,0088$ & 0,0153 \\
\hline & & $(0,0051)$ & $(0,4015)$ & $(0,5026)$ & $(0,3351)$ \\
\hline \multirow{6}{*}{$\begin{array}{c}\text { Qualificação } \\
\text { profissional do } \\
\text { professor }\end{array}$} & \multirow{2}{*}{$\begin{array}{l}\text { Formação continuada do } \\
\text { professor }\end{array}$} & 0,0026 & $-0,0107$ & 0,0122 & \\
\hline & & 0,3426 & 0,0794 & 0,0179 & \\
\hline & \multirow{2}{*}{$\begin{array}{l}\text { Formação adequada do } \\
\text { professor }\end{array}$} & 0,0132 & 0,0560 & 0,0009 & \\
\hline & & 0,0861 & 0,0012 & 0,9464 & \\
\hline & \multirow{2}{*}{$\begin{array}{l}\text { Professores com pós- } \\
\text { graduação }\end{array}$} & $-0,0096$ & 0,0221 & $-0,0099$ & \\
\hline & & $\mathbf{0 , 0 3 3 5}$ & 0,0262 & 0,2325 & \\
\hline \multirow{4}{*}{ Desorganização social } & \multirow{2}{*}{ Mães adolescentes } & 0,5890 & 1,1420 & $-0,0796$ & \\
\hline & & 0,0000 & 0,0000 & 0,6954 & \\
\hline & \multirow{2}{*}{ Densidade demográfica } & 0,0001 & 0,0001 & 0,0001 & \\
\hline & & 0,4241 & 0,5801 & 0,6347 & \\
\hline \multirow{6}{*}{ Econômicas } & \multirow{2}{*}{ Emprego formal } & 0,3275 & $-0,1633$ & 1,2171 & $-0,0057$ \\
\hline & & 0,0015 & 0,4646 & 0,0000 & $(0,3582)$ \\
\hline & \multirow{2}{*}{ Consumo energia elétrica } & $-0,0920$ & $-0,1706$ & $-0,1618$ & \\
\hline & & 0,2117 & 0,2938 & 0,2355 & \\
\hline & \multirow{2}{*}{ Rendimento } & 0,4095 & 0,2024 & $\mathbf{0 , 7 7 0 7}$ & 0,0451 \\
\hline & & 0,0015 & 0,4668 & 0,0013 & $(0,0080)$ \\
\hline \multirow{4}{*}{ Categóricas } & \multirow{2}{*}{$\begin{array}{l}\text { Município de grande e } \\
\text { médio porte }\end{array}$} & 0,2449 & 0,0544 & 0,2447 & $-0,0069$ \\
\hline & & 0,0241 & 0,7480 & 0,2198 & $(0,4467)$ \\
\hline & \multirow{2}{*}{ Litoral } & $-0,0178$ & 0,3328 & $-0,4720$ & \\
\hline & & 0,8161 & 0,1623 & 0,0012 & \\
\hline \multirow{2}{*}{\multicolumn{2}{|c|}{ Constante }} & $-5,0738$ & 2,1801 & $-10,1559$ & 2,5932 \\
\hline & & 0,0002 & $\mathbf{0 , 4 5 9 8}$ & 0,0001 & 0,691448 \\
\hline \multicolumn{2}{|c|}{ Número de observações } & 120 & 120 & 120 & 119 \\
\hline \multicolumn{2}{|l|}{$\mathbf{R}^{2}$} & $\mathbf{0 , 9 0 8 6}$ & 0,7146 & $\mathbf{0 , 8 6 9 3}$ & 0,5102 \\
\hline Durbin-Wa & son & 1,6904 & 1,8179 & 1,4778 & 1,4856 \\
\hline
\end{tabular}

Fonte: Elaboração própria.

\section{CONSIDERAÇÕES FINAIS}

Revista de Gestão, Finanças e Contabilidade - v. 10, n. 2, p. 86-107, mai./ago. 2020 ISSN 2238-5320, UNEB, Salvador/BA 
O presente trabalho buscou identificar as variáveis socioeconômicas e estruturais com maior nível de associação à violência e criminalidade na Bahia durante os anos de 2015 e 2017. Para tanto, utilizou-se uma metodologia de dados em painel a fim de identificar a relação desses vetores com o fenômeno estudado. Os principais resultados apontam que no contexto da Bahia a estrutura familiar destaca-se como elemento chave na prevenção da violência e criminalidade. Por sua vez, nos municípios com mais oportunidades econômicas, a qualidade da educação ofertada ao grupo de pré-adolescentes é preponderante para explicação de todos os tipos de crimes. Essa observação indica que políticas de prevenção à violência e criminalidade desenvolvidas considerando o âmbito escolar devem variar conforme o contexto socioeconômico do município em que a escola esteja inserida.

O estudo também apontou uma alteração de padrão na ocorrência de crimes patrimoniais em que não foi observada relação destes com a dimensão educação. Isso pode indicar que os perpetradores dos crimes de natureza econômica não estão mais sob influência da escola. E para os homens jovens os principais achados sugerem que maiores oportunidades econômicas não se traduzem em uma redução imediata dos homicídios desse grupo social. Estes resultados podem indicar que os mecanismos efetivos para a recuperação de uma parte dos jovens envolvidos em atividades ilícitas não surtiriam efeito imediato, requerendo do poder público o acionamento de outros instrumentos.

Por fim, não foi possível identificar todos os fatores determinantes para a violência e criminalidade na Bahia. Uma parte desses vetores não são identificados ou passíveis de mensuração. Entre eles é possível destacar a cultura criminosa e que está associada, sobretudo, a disputa entre grupos rivais no âmbito do comércio de drogas ilícitas e tráfico de armas. Associado a isso, está a persistência do clima de instabilidade social. Sendo assim, propostas de intervenções públicas de natureza preventiva contra a violência e criminalidade devem privilegiar o campo social focalizadas nos bairros e comunidades mais vulneráveis socioeconomicamente e onde se encontram as maiores incidências de crimes.

\section{REFERÊNCIAS}

ADORNO, S. Democracy in progress in contemporary Brazil: corruption, organized crime, violence and new paths to the rule of law. International Journal of Criminology and Sociology, Ontário, v. 2, p. 409-425, 2013.

ANDRADE, M.; LISBOA, M. Desesperança de vida: homicídios em Minas Gerais, Rio de Janeiro e São Paulo no período de 1981/97. In: HENRIQUES, R. (org.). Desigualdade e pobreza no Brasil. Rio de Janeiro: IPEA, 2000. cap. 12, p. 347-384.

ANUÁRIO BRASILEIRO DE SEGURANÇA PÚBLICA: 2011. São Paulo: Fórum Brasileiro de Segurança Pública, v. 5, 2011.

ANUÁRIO BRASILEIRO DE SEGURANÇA PÚBLICA: 2019. São Paulo: Fórum Brasileiro de Segurança Pública, v. 13, 2019.

ARAÚJO JR., A. Raízes econômicas da criminalidade violenta no Brasil: um estudo usando microdados e pseudopainel - 1981/1986. Revista de Economia e Administração, São Paulo, v. 1, n. 3, p. 1-34, 2002.

ANJOS JÚNIOR, O. R. dos; LOMBARDI FILHO, S. C.; AMARAL, P. V. M. do.

Determinantes da criminalidade na região sudeste do Brasil: uma aplicação de painel espacial. 
Economía, Sociedad y Territorio, Toluca, v. 18, n. 57, p. 525-556, mayo/ago. 2018.

BAHIA. Secretaria de Segurança Pública. Base de dados criminais. Salvador: SSP, 2019. Documento em Excel.

BAHIA. Secretaria de Segurança Pública. Plano Estratégico de Segurança Pública: 20162025. Salvador: EGBA, 2017. Disponível em:

http://www.ssp.ba.gov.br/arquivos/File/Projetos/PLANESP.pdf. Acesso em: 10 fev. 2019.

BEATO, C. Determinantes da criminalidade em Minas Gerais. Revista Brasileira de

Ciências Sociais, São Paulo, v. 13, n. 37, p. 74-87, 1998.

BECKER, G. Crime and punishment: an economic approach. Journal of Political Economy, Chicago, v. 76, n. 2, p. 169-217, mar./abr. 1968. Disponível em:

https://www.journals.uchicago.edu/doi/pdfplus/10.1086/259394. Acesso em: 1 dez. 2017.

BECKER, K. L.; KASSOUF, A. L. Uma análise do efeito dos gastos públicos em educação sobre a criminalidade no Brasil. Economia e Sociedade, Campinas, v. 26, n. 1, p. 215-242, 2017.

BLOCK, M. K.; HEINEKE, J. M. A labor theoretic analysis of the criminal choice. The American Economic Review, [s. l.], v. 65, n. 3, p. 314-325, 1975.

BRASIL. [Constituição (1988)]. Constituição da República Federativa do Brasil. Brasília: Senado, 1988. Disponível em: Planalto. gov. br: http://www. planalto. gov.

br/ccivil_03/constituicao/constituicaocompilado. Htm. Acesso em: 4 dez. 2018.

BRASIL. Lei $n^{\circ}$ 6.015, de 31 de dezembro de 1973. Dispõe sobre os registros públicos, e dá outras providências. Diário Oficial [da] República Federativa do Brasil, Brasília, DF, 31 dez. 1973. Disponível em: http://www.planalto.gov.br/ccivil_03/LEIS/L6015consolidado.htm. Acesso em: 5 dez. 2018.

BRASIL. Decreto-Lei nº 2.848, de 07 de dezembro de 1940. Código Penal. Diário Oficial [da] União, Rio de Janeiro, 31 dez. 1940. Disponível em:

http://www.planalto.gov.br/ccivil_03/decreto-lei/del2848compilado.htm. Acesso: 28 out. 2020.

BRASIL. Ministério da Saúde. Secretaria Executiva. Datasus: informações de saúde: estatísticas vitais 1979-2017. Disponível em: http://datasus.saude.gov.br/informacoes-desaude/tabnet/estatisticas-vitais. Acesso em: 30 jan. 2019a.

BRASIL. Secretaria Nacional de Segurança Pública. Memorando no 19/2016. Brasília: SENASP, 19 fev. 2016. Assunto: Crimes Violentos Letais Intencionais - CVLI. Disponível em:

http://www.consultaesic.cgu.gov.br/busca/dados/Lists/Pedido/Attachments/455006/RESPOS

TA_PEDIDO_RESPOSTA\%20SIC\%20-\%2008850000319201610.pdf. Acesso em: 1 mar. 2017.

BRASIL. Ministério da Fazenda, Secretaria do Tesouro Nacional. Boletim de finanças dos entes subnacionais. Brasília: Ministério da Fazenda, 2019b. Disponível em: https://sisweb.tesouro.gov.br/apex/cosis/thot/transparencia/arquivo/30407:981194:inline:9731 352684720. Acesso em: 20 jan. 2020. 
BUONANNO, P.; LEONIDA, L. Criminal activity and education: evidence from italian regions. Bergamo, IT: Università di Bergamo, 2005. Disponível em: https://aisberg.unibg.it/retrieve/handle/10446/191/1913/WPEco03\%282005\%29Buonanno.pd f. Acesso em: 1 dez. 2017.

CAIRES, F. Fatores socioeconômicos e dinâmicas espaciais da evolução da criminalidade na Bahia. 2017. 75 f. Dissertação (Mestrado em Economia Regional e Políticas Públicas) Departamento de Ciências Econômicas, Universidade Estadual de Santa Cruz, Ilhéus, 2017.

CANO, I.; SOARES, G. As teorias sobre as causas da criminalidade. Rio de Janeiro: IPEA, 2002.

CARRETS, F. D.; OLIVEIRA, J. de; MENEZES, G. R. A criminalidade no Rio Grande do Sul: uma análise espacial para anos de 2005, 2010 e 2015. Perspectiva Econômica, São Leopoldo, v. 14, n. 1, p. 33-46, jan./jun. 2018.

CERQUEIRA, D. Causas e consequências do crime no Brasil. 2010. 196 f. Tese (Doutorado em Economia) - Pontifícia Universidade Católica do Rio de Janeiro, Rio de Janeiro, 2010.

CERQUEIRA, D. et al. Indicadores multidimensionais de educação e homicídios nos territórios focalizados pelo Pacto Nacional pela Redução de Homicídios. Brasília: IPEA, 2016.

CERQUEIRA, D.; LOBÃO, W. Determinantes da criminalidade: uma resenha dos modelos teóricos e resultados empíricos. Rio de Janeiro: IPEA, 2003. (Texto para discussão, 956).

CLEMENTE, A.; WELTERS, A. Reflexões sobre o modelo original da economia do crime. Revista de Economia, Curitiba, v. 33, n. 2, p. 139-157, jul./dez. 2007.

COELHO, E. A criminalidade urbana violenta. Dados, Rio de Janeiro, v. 31, n. 2, p. 145-183, 1988.

COHEN, L. E.; FELSON, M. Social change and crime rate trends: a routine activity approach. American Sociological Review, [s. l.], v. 44, n. 4, p. 588-608, Aug. 1979.

CORNWELL, C.; TRUMBULL, W. Estimating the economic model of crime with panel data. The Review of Economics and Statistics, Cambridge, v. 76, n. 2, p. 360-366, May, 1994.

Disponível em:

https://www.amherst.edu/media/view/121570/original/CornwellTrumbullCrime\%2BElasticiti es.pdf. Acesso em: $1 \mathrm{dez} .2017$.

CRUZ, F. V.; ARAÚJO, A. F. V. Análise da criminalidade em Palmas-TO: uma abordagem econométrica da violência urbana. Informe GEPEC, Toledo, v. 16, n. 2, p. 170-185, jul./dez. 2012.

EHRLICH, I. Participation in illegitimate activities: a theoretical and empirical investigation. Journal of Political Economy, Chicago, v. 81, n. 3, p. 526-536, May/June, 1973. Disponível em: https://www.journals.uchicago.edu/doi/abs/10.1086/260058. Acesso em: 1 dez. 2017.

ERVILHA, G. T.; LIMA, J. E. de. Um método econométrico na identificação dos determinantes da criminalidade municipal: a aplicação em Minas Gerais, Brasil (2000-2014).

Economía, Sociedad y Territorio, Toluca, v. 19, n. 59, p. 1059-1086, 2019. 
FARIAS, R. de; MORÉ, C. O. O. Repercussões da gravidez em adolescentes de 10 a 14 anos em contexto de vulnerabilidade social. Psicologia: reflexão e crítica, Porto Alegre, v. 25, n. 3, 2012.

FERREIRA, L.; MATTOS, E.; TERRA, R. O papel das guardas municipais na redução da criminalidade: evidências empíricas para um painel de municípios paulistas. Pesquisa e Planejamento Econômico, Rio de Janeiro, v. 46, n. 2, p. 151-181, ago. 2016.

GUJARATI, D. N. Basic econometrics. 5. ed. New York: Tata McGraw-Hill Education, 2009.

HANUSHEK, E. A.; RIVKIN, S. G. School quality and the black-white achievement gap. Massachusetts: NBER, 2006. (Working paper, 12651). Disponível em: https://www.nber.org/papers/w12651. Acesso em: 1. set. 2019

HOLTZ-EAKIN, D.; NEWEY, W.; ROSEN, H. Estimating vector autoregressions with panel data. Econometrica, Ohio, v. 56, n. 6, p. 1371-1396, Nov. 1998.

JORGE, M. Análise da causalidade dos homicídios em Sergipe sob a ótica da economia do crime no período de 2007 a 2010. Revista de Economia Mackenzie, São Paulo, v. 11, n. 3, p. 90-115, set./dez. 2013. Disponível em:

http://editorarevistas.mackenzie.br/index.php/rem/article/view/7783/5208. Acesso em: 1 dez. 2017.

JUSTUS, M.; KAHN, T.; KAWAMURA, H. Relationship between income and repeat criminal victimization in Brazil. EconomiA, Niterói, n. 16, n. 3, p. 295-309, Sept./Dec. 2015. Disponível em: https://www.econstor.eu/bitstream/10419/179601/1/economia_v16_i3_p295309.pdf. Acesso em: 1 dez. 2017.

KAHN, T. Crescimento econômico e criminalidade: uma interpretação da queda dos crimes no Sudeste e aumento no Norte/Nordeste. Revista Brasileira de Segurança Pública, São Paulo, v. 7, n. 1, p. 152, 2013. Disponível em:

http://revista.forumseguranca.org.br/index.php/rbsp/article/view/209. Acesso em: 1 dez. 2017.

KELLY, M. Inequality and crime. Review of Economics and Statistics, Cambridge, MA, v. 82, n. 4, p. 530-539, Mar. 2000. Disponível em:

https://econpapers.repec.org/article/tprrestat/v_3a82_3ay_3a2000_3ai_3a4_3ap_3a530539.htm. Acesso em: 1 dez. 2017.

LEVANDOWSKI, D. C.; PICCININI, C. A.; LOPES, R. C. S. Maternidade adolescente. Estudos de Psicologia, Campinas, v. 25, n. 2, p. 251-263, abr./jun. 2008.

LIMA, R.; BORGES, D. Estatísticas criminais do Brasil. In: LIMA, R.; RATTON, J.; AZEVEDO, R. (org.). Crime, política e justiça no Brasil. São Paulo: Contexto, 2014.

MANSO, B. P.; DIAS, C. N. A guerra: a ascensão do PCC e o mundo do crime no Brasil. Editora Todavia SA, 2018.

MENEZES FILHO, N. A. Os determinantes do desempenho escolar do Brasil. São Paulo: IFB, 2007.

NÓBREGA JR., J. M. P. Distribuição de renda e sua relação com os homicídios na Região Nordeste do Brasil. Revista LEVS, Marília, v. 18, p. 147-155, 2016. 
Santana, Santos e Freitas (2020)

Determinantes da Violência e Criminalidade

na Bahia Entre os Anos de 2015 a 2017

NÓBREGA JR., J. M. P. Violência homicida no Nordeste brasileiro: dinâmica dos números e possibilidades causais. Revista Dilemas IFCS-UFRJ, Rio de Janeiro, v. 10, n. 3, p. 553-572, 2017. Disponível em: https://revistas.ufrj.br/index.php/dilemas/article/view/14563/9823. Acesso em: 1 dez. 2017.

ORGANIZAÇÃO MUNDIAL DA SAÚDE. CID-10: classificação estatística internacional de doenças e problemas relacionados à saúde. São Paulo: Edusp, 1994. v. 1.

PERES, M. F. T. Violência por armas de fogo no Brasil: relatório nacional. São Paulo: NEV/USP, 2004.

SAMPSON, R.; GROVES, W. Community structure and crime: testing social-disorganization theory. American Journal of Sociology, Chicago, v. 94, n. 4, p. 774-802, 1989. Disponível em:

https://dash.harvard.edu/bitstream/handle/1/3226955/Sampson_CommunityStructureCrime.pd f? sequence=2\&isAllowed=y. Acesso em: 1 dez. 2017.

SANTANA, J. Violência armada na Bahia: uma análise em painel de dados dos fatores determinantes para os anos de 2000 e 2010. 2018. 151 f. Dissertação (Mestrado em Administração) - Escola de Administração, Universidade Federal da Bahia, Salvador, 2018.

SANTOS, M. J. Dinâmica temporal da criminalidade: mais evidências sobre o "efeito inércia" nas taxas de crimes letais nos estados brasileiros. Revista EconomiA, Niterói, v. 10, n. 1, p. 169-194, 2009.

SHAW, C. R.; MCKAY, H. D. Juvenile delinquency and urban areas. Chicago: University of Chicago Press, 1942.

SILVA, B.; MARINHO, F. C. Urbanismo, desorganização social e criminalidade. Crime, Polícia e Justiça no Brasil. São Paulo: Editora Contexto, p. 23-29, 2014.

SOARES FILHO, A. Vitimização por homicídios segundo características de raça no Brasil. Revista de Saúde Pública, São Paulo, v. 45, n. 4, p. 745-455, 2011.

SOARES, G. A. D. Não matarás: desenvolvimento, desigualdade e homicídios. Rio de Janeiro: FGV, 2008.

SUPERINTENDÊNCIA DE ESTUDOS ECONÔMICOS E SOCIAIS DA BAHIA (SEI). Informações municipais. 2018. Disponível em:

https://www.sei.ba.gov.br/index.php?option=com_wrapper\&view=wrapper\&Itemid=266. Acesso em: 01 jun. 2020.

VEYSEY, B. M.; MESSNER, S. F. Further testing of social disorganization theory: An elaboration of Sampson and Groves's “community structure and crime”. Journal of Research in Crime and Delinquency, v. 36, n. 2, p. 156-174, 1999.

WAISELFISZ, J. Mapa da violência 2016: homicídios por armas de fogo no Brasil. Rio de Janeiro: FLACSO Brasil, 2016.

WOOLDRIDGE, J. M. Introdução à econometria: uma abordagem moderna. São Paulo: Cengage, 2010.

WORLD HEALTH ORGANIZATION. The world health report 2002: reducing risks, 
promoting healthy life. Geneva: WHO, 2002. Disponível em:

https://apps.who.int/iris/bitstream/handle/10665/42510/WHR_2002.pdf;jsessionid=9BB1CD2 2A1B3813FA3FE99F518ECCF7E?sequence=1. Acesso em: $1 \mathrm{dez} .2017$.

WORLD HEALTH ORGANIZATION. World Drug Report 2019.: Global Overview of Drug Demand and Supply. Disponível:

https://wdr.unodc.org/wdr2019/prelaunch/WDR19_Booklet_2_DRUG_DEMAND.pdf. Acesso em: 10 out. 2019.

ZALUAR, A. A máquina e a revolta. São Paulo: Brasiliense, 1985.

ZALUAR, A. Urban violence, citizenship and public policies. International Journal of Urban and Regional Research, [s. l.], v. 17, n. 1, p. 56-66, Mar. 1993. 